University of Nebraska - Lincoln

DigitalCommons@University of Nebraska - Lincoln

Eating rate during a fixed-portion meal does not affect postprandial appetite and gut peptides or energy intake during a subsequent meal

J. Phillip Karl

US Army Research Institute of Environmental Medicine, james.p.karl@us.army.mil

Andrew J. Young

US Army Research Institute of Environmental Medicine

Scott J. Montain

US Army Research Institute of Environmental Medicine

Follow this and additional works at: https://digitalcommons.unl.edu/usarmyresearch

Part of the Operations Research, Systems Engineering and Industrial Engineering Commons

Karl, J. Phillip; Young, Andrew J.; and Montain, Scott J., "Eating rate during a fixed-portion meal does not affect postprandial appetite and gut peptides or energy intake during a subsequent meal" (2011). US Army Research. 131.

https://digitalcommons.unl.edu/usarmyresearch/131

This Article is brought to you for free and open access by the U.S. Department of Defense at DigitalCommons@University of Nebraska - Lincoln. It has been accepted for inclusion in US Army Research by an authorized administrator of DigitalCommons@University of Nebraska - Lincoln. 


\title{
Eating rate during a fixed-portion meal does not affect postprandial appetite and gut peptides or energy intake during a subsequent meal ${ }^{2}$
}

\author{
J. Philip Karl *, Andrew J. Young, Scott J. Montain \\ Military Nutrition Division, US Army Research Institute of Environmental Medicine, Natick, MA, 01760, USA
}

\section{A R T I C L E I N F O}

Article history:

Received 3 August 2010

Received in revised form 4 January 2011

Accepted 7 January 2011

\section{Keywords}

Eating rate

Satiety

Cholecystokinin

Glucagon-like peptide-1

Pancreatic polypeptide

Peptide-YY

\begin{abstract}
A B S T R A C T
Eating rate has recently been shown to influence energy intake and appetite during an ad libitum meal, and alter postprandial secretion of glucagon-like peptide-1 (GLP-1) and peptide-YY (PYY) following a fixed-portion meal. Whether these effects influence satiety, as measured by energy intake at the subsequent meal, is unclear. We manipulated eating rate during a fixed-portion meal in order to examine how eating behavior and associated periprandial and postprandial responses of putative endocrine mediators of appetite would affect energy intake at the following meal in fifteen non-obese $\left(B M I<25 \mathrm{~kg} / \mathrm{m}^{2}\right)$ and ten obese $\left(\mathrm{BMI} \geq 30 \mathrm{~kg} / \mathrm{m}^{2}\right)$ healthy adult men and women. In random order, each participant consumed a standardized, fixed-portion meal in 7 (FM), 14 (MM) or 28 (SM) minutes. Fullness, measured by the Satiety Labeled Intensity Magnitude (SLIM) scale, serum insulin, glucose, leptin, pancreatic polypeptide (PP), PYY, GLP-1, neuropeptide-Y, and plasma cholecystokinin (CCK) were measured for $3 \mathrm{~h}$ following the fixed-portion meal. Ad libitum energy intake at the next meal was then measured. Eating slowly delayed time to peak fullness $(P \leq 0.05)$, but did not alter peak fullness. Peak PP concentrations were attenuated during FM compared to MM and SM $(P \leq 0.05)$ and were reached earlier during MM compared to SM $(P \leq 0.05)$. A meal-by-time interaction $(P \leq 0.05)$, but no differences in AUC, peak, or time to peak were observed for CCK. No additional between meal differences in AUC, peak or time to peak for any endocrine mediator of appetite was observed. Ad libitum energy intake was not different between trials. In conclusion, the rate at which a fixed-portion meal is consumed does not appear to alter satiety despite a small effect on PP and CCK responses. Published by Elsevier Inc.
\end{abstract}

\section{Introduction}

The prevalence of overweight and obesity is increasing worldwide [1]. Weight gain ultimately results from an imbalance between energy intake and expenditure. Though hedonic and environmental factors contribute, physiologic mechanisms exist to mediate energy balance, and behavioral strategies that manipulate those mechanisms may prove efficacious for healthy weight management.

Homeostatic regulation of energy balance is complex, involving an integrated network of neural and hormonal signals. Hormones including leptin and insulin are secreted in proportion to body energy stores, reflecting long-term energy balance [2]. These long-acting signals modify sensitivity to enteroendocrine peptides secreted during ingestion and the post-ingestive period that mediate short-term energy

\footnotetext{
is The opinions or assertions contained herein are the private views of the authors and are not to be construed as official or as reflecting the views of the Army or the Department of Defense. Any citations of commercial organizations and trade names in this report do not constitute an official Department of the Army endorsement of approval of the products or services of these organizations. Study funded by the US Army Medical Research and Materiel Command. Portions of this manuscript were presented at the 2009 Obesity Society Annual Meeting 24-28 October and the 2010 American College of Sports Medicine Annual Meeting 2-5 June.

* Corresponding author. Tel.: +1 508233 5140; fax: +1 5082335833

E-mail address: james.p.karl@us.army.mil (J.P. Karl).
}

intake, such as cholecystokinin (CCK), pancreatic polypeptide (PP), peptide-tyrosine tyrosine (PYY), and glucagon-like peptide-1 (GLP-1) [3]. Through both endocrine and neural mechanisms, these peptides stimulate appetite centers located in the hindbrain, modulating expression of neuropeptides such as neuropeptide-Y (NPY) [4]. Ultimately the anorexigenic and orexigenic effects resulting from the integration of these signals are thought to influence energy balance by mediating sensations of hunger and fullness [2,3].

In addition to factors such as macronutrient composition [5] and viscosity [6], how one eats may affect postprandial responses of the enteroendocrine hormones that mediate appetite. Eating fast has been associated with excess energy intake and overweight [7-12], while eating slowly is hypothesized to discourage excess energy intake by allowing time for peripheral satiation signals to be consciously recognized before overeating occurs. Recent experimental trials support a relationship between eating rate and energy intake during a single ad libitum meal [13-15], providing empirical evidence that eating behavior can mediate satiation (i.e., the processes during a meal acting to terminate eating) [16] thereby altering energy intake.

The ubiquity of portion-controlled meals and snacks, and the tendency for portion size to influence consumption [17] suggest a need to examine not only eating behaviors that may influence satiation, but to also identify eating behaviors that influence satiety (i.e., feelings of fullness throughout the intermeal interval) [16] after a 
fixed-portion is consumed. Rather than, or in addition to, altering energy intake during a meal, eating behaviors that influence satiety would be expected to promote weight management by altering energy intake at a subsequent meal or affecting the length of the intermeal interval. Eating a fixed-portion slowly relative to eating the same portion quickly was recently shown to increase PYY and GLP-1 responses during the early to mid postprandial period, providing the first evidence of a physiologic mechanism by which eating rate may influence energy intake [18]. Unfortunately, neither energy intake at a subsequent meal nor the time elapsed until initiation of the next meal was measured; therefore, whether the documented effects influence satiety remains unclear.

To further explore the effects of eating rate and associated postprandial appetite and peripheral enteroendocrine responses on energy intake during the subsequent meal, we measured fullness and putative endocrine mediators of appetite following consumption of a standardized, fixed-portion meal consumed at three different eating rates. Ad libitum energy intake at the next meal provided an objective assessment of satiety [16]. To determine if weight status influences the effects of eating rate on postprandial hormone responses and satiety, both non-obese and obese volunteers were recruited. We hypothesized that altering eating rate would affect postprandial fullness ratings concomitant to altered concentrations of enteroendocrine hormones in both non-obese and obese adults, and that these changes would result in differences in energy intake at the subsequent meal.

\section{Materials and methods}

\subsection{Volunteers}

Non-obese (body mass index $[\mathrm{BMI}]<25 \mathrm{~kg} / \mathrm{m}^{2}$ ) and obese $\left(\mathrm{BMI} \geq 30 \mathrm{~kg} / \mathrm{m}^{2}\right)$ men and women, $18-55$ years of age, were recruited from the U.S. Army Soldier Systems Center, Natick, MA, USA and surrounding area. Exclusion criteria included previous diagnosis with any disease affecting metabolism, chronic use of medications affecting metabolism and/or appetite, $\geq 2.2 \mathrm{~kg}$ weight change during the 3 months preceding participation, pregnancy, allergies to or stated dislike of the test foods, and clinically diagnosed eating disorder or a score of $\geq 20$ on the Eating Attitudes Test [19]. The study was approved by the Human Use Review Committee at the U.S. Army Research Institute of Environmental Medicine. Human volunteers participated in this study after providing their free and informed voluntary consent. Investigators adhered to US Army Regulation 7025 and US Army Medical Research and Materiel Command regulation 70-25 on the use of volunteers in research.

\subsection{Study design}

Anthropometric characteristics and normal eating rate were measured during the screening period. BMI was calculated from measured height and weight. Fat free mass was measured by dual energy X-ray absorptiometry (Lunar iDXA, GE Healthcare, Madison, WI, USA) and used to estimate resting energy expenditure (REE) [20]. Normal eating rate was measured by instructing volunteers to consume a standardized, fixed-portion meal (described below) on a portable eating monitor (described below) at their usual pace.

The experimental period consisted of three separate visits occurring on non-consecutive days over at least two weeks. No more than two weekly visits were conducted. Volunteers began each of their three visits at the same time, between 0700 and 0830, and following a $12 \mathrm{~h}$ fast. Volunteers were instructed to adhere to their normal diet and physical activity patterns on the day preceding each study visit, and to abstain from strenuous physical exertion, caffeine and smoking during the $12 \mathrm{~h}$ fast. Twenty-four hour diet and activity recalls were completed during each visit to ensure compliance with these instructions.

During each of the three experimental visits volunteers were provided two meals; first consuming a standardized, fixed-portion meal followed $3 \mathrm{~h}$ later by an ad libitum meal. Meal duration of the fixed-portion meals was set at either 7 (FM), 14 (MM) or 28 (SM) minutes. Each volunteer received all three meals. Within each weight status cohort, volunteers were randomly assigned to a meal order schedule that was designed so that each meal would be served five times during experimental days 1, 2 and 3 for every 15 volunteers enrolled (e.g., SM was served as the 1 st test meal 5 times, the 2 nd test meal 5 times and the 3rd test meal 5 times). Fig. 1 depicts the study testing schedule during each experimental visit. No more than 15 min prior to beginning the fixed-portion meal, an indwelling venous catheter was placed and a fasting blood sample collected. Blood was then sampled at 15, 30, 45, 60, 90, 120 and 180 min after the first bite. Fullness was rated at each blood sample. During the postprandial period volunteers read quietly or watched TV, only ambulating to use the restroom. The catheter was removed at $180 \mathrm{~min}$ and volunteers were presented with the ad libitum meal. Volunteers were then instructed to eat until "comfortably full" and to take as much time as necessary. More food than could be consumed was provided as there was always food left on the plate at meal completion. Once finished, fullness was measured. Following each meal volunteers were asked to rate meal "appearance," “odor," "flavor," "texture," and "overall acceptability" on a 9-point Likert scale.

\subsection{Meals}

The standardized, fixed-portion meal was Hormel® corned beef hash (31\% energy from carbohydrate, $40 \%$ energy from fat, $29 \%$ energy from protein). The mixed macronutrient content of this meal was expected to elicit measureable postprandial responses from each measured variable. Volunteers consumed a portion equivalent in energy content to $40 \%$ of their respective REE. The ad libitum meal was Stouffer's $₫$ Lasagna (41\% energy from carbohydrate, 36\% energy from fat, $23 \%$ energy from protein).

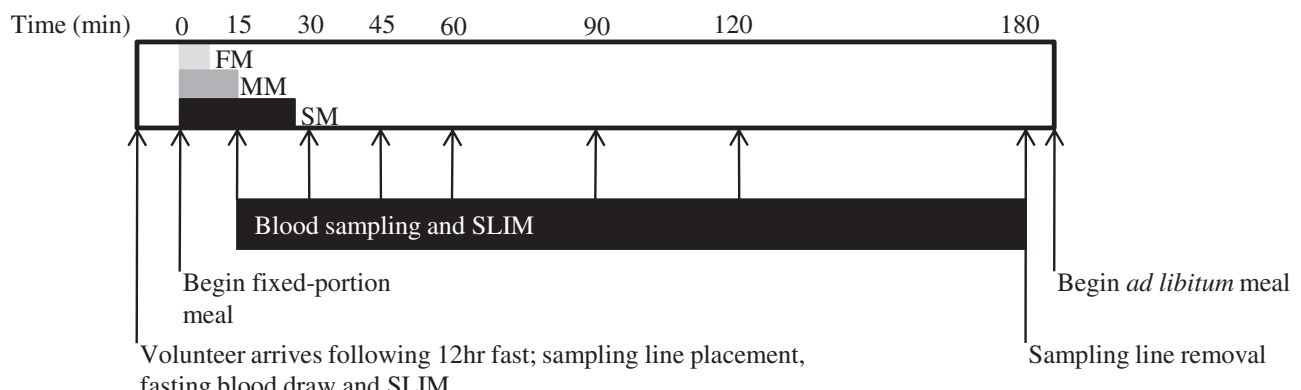

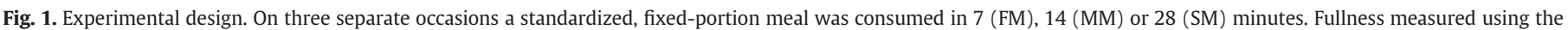
Satiety Labeled Intensity Magnitude (SLIM) scale. 
To prevent confounding from discretionary fluid intake, volunteers were provided with $240 \mathrm{~g}$ water during both the fixed-portion and ad libitum meals. Volunteers were instructed to finish the water before meal completion and no additional water was permitted. During the postprandial period volunteers were provided with $360 \mathrm{~g}$ of water. The fluid was intended to ensure obtainment of adequate blood sample volumes and for volunteer comfort. Volunteers were instructed to consume all of the water prior to the ad libitum meal; no additional water was permitted.

\subsection{Eating monitor}

Eating rate was manipulated using a portable, calibrated scale interfaced with a small computer and monitor (Mandometer, AB Mando, Huddinge, Sweden). A pre-programmed eating curve, presented as a straight line intersecting the vertical axis (mass) at total mass of the standardized meal (portion equivalent to $40 \%$ of volunteer's estimated REE) and the horizontal axis (time) at the programmed meal duration ( 7 , 14 or $28 \mathrm{~min}$ ) was displayed on the monitor. As the volunteer ate, the amount of food removed from the plate over time was plotted in realtime. By matching the real-time eating curve to the pre-programmed eating curve, volunteers complied with the prescribed eating rate, eating at a consistent rate throughout the meal.

\subsection{Satiety Labeled Intensity Magnitude scale}

Hunger and fullness was measured using the Satiety Labeled Intensity Magnitude (SLIM) scale. The SLIM has been shown to be a sensitive, reliable, and easy-to-use scale for measuring perceived hunger and fullness [21]. Briefly, the scale is a vertical, $100 \mathrm{~mm}$, bidirectional hunger/fullness scale anchored by the terms "greatest imaginable fullness" and "greatest imaginable hunger." The volunteer is directed to mark the scale anywhere along the axis corresponding to their level of hunger or fullness "right now." A rating anywhere above the midpoint of the scale indicates that some degree of fullness is perceived. Throughout the manuscript, the term fullness is used to describe SLIM ratings at or above the midpoint of the scale.

\subsection{Biological sample collection and analysis}

Blood samples were collected into tubes containing either EDTA for plasma separation or clotting activator for serum separation via an indwelling venous catheter placed in the antecubital space. Immediately after collection, $25 \mu \mathrm{L}$ aprotinin/mL whole blood was added to serum and plasma samples. In the obese cohort $10 \mu \mathrm{L}$ dipeptidyl peptidase-IV (DPP-IV) inhibitor/mL whole blood was also added to serum samples for GLP-1 measurement. DPP-IV inhibitor was not added to serum samples in the non-obese cohort; therefore, only GLP-1 values from the obese cohort are presented. Samples were processed, frozen immediately, shipped to Pennington Biomedical Research Center, Baton Rouge, LA, USA and placed in storage. Following completion of data collection for each cohort (non-obese and obese), samples were analyzed for GLP-1, CCK, glucose, insulin, PYY, PP, leptin, and NPY. Plasma CCK was measured by radioimmunoassay (Alpco Diagnostics, Windham, $\mathrm{NH}$, USA). The sensitivity of the assay was $0.78 \mathrm{pmol} / \mathrm{L}$ and the inter-assay $\mathrm{CV}<14.4 \%$. Serum glucose was measured using the Beckman Coulter DXC 600 Pro (Fullerton, CA, USA). Serum insulin, total PYY (PYY ${ }_{3-36}$ and PYY 1-36), PP, active GLP-1 (GLP-1 1 -36amide and GLP-1 1 -37), and leptin were measured using a multiplex assay (Milliplex MAP; Millipore, Billerica, MA, USA) with an inter-assay CV of $<19 \%$. Sensitivity of the assay was $137 \mathrm{pg} / \mathrm{mL}$ for insulin, $13.7 \mathrm{pg} / \mathrm{mL}$ for PYY, PP and GLP-1, and $0.14 \mathrm{ng} / \mathrm{mL}$ for leptin. Serum NPY was measured by radioimmunoassay (Alpco Diagnostics, Windham, NH, USA). The sensitivity of the assay was $9.4 \mathrm{pmol} / \mathrm{L}$ and the inter-assay $\mathrm{CV}<16.7 \%$.

\subsection{Statistical analysis}

Statistical analysis was performed using commercially available statistical software (SPSS 17.0; SPSS Inc., Chicago, IL, USA). Descriptive statistics are presented as mean \pm SD or median (range) as appropriate. The time course of the SLIM, glucose, insulin, GLP-1, PP, PYY, CCK, leptin and NPY responses were plotted for each individual, and peak and time to peak (TP) values determined. The trapezoidal method was used to calculate the area under the curve (AUC) with respect to increase for SLIM ratings and endocrine mediators of appetite [22]. Normality was determined using the Shapiro-Wilk test. Repeated measures ANOVA with post-hoc Bonferroni corrections was used to determine between meal differences in peak, AUC and ad libitum intake. To further explore differences in ad libitum intake, paired samples t-tests were used to compare differences in intake between SM and FM. Friedman's ANOVA was used to determine between meal differences in TP. Wilcoxon signed-ranks tests were used to verify significant differences following a significant result from Friedman's ANOVA. Significance was set at $P \leq 0.05$.

The two study groups (obese and non-obese adults) were included in the experimental design to assess if weight status could be a possible confounding factor. After observing that the general patterns of the fullness and enteroendocrine responses to manipulation of eating rate were similar within each cohort, and that eating rate manipulation had no effect on energy intake at the subsequent meal in either cohort, the two groups were combined and analyzed together. The data presented are the outcomes of the combined analysis.

\section{Results}

Twenty-five, 15 non-obese ( 8 male and 7 female) and 10 obese ( 8 male and 2 female), healthy adults participated. Volunteer characteristics are presented in Table 1. Fasting concentrations of blood markers did not differ by meal within individuals; therefore, fasting concentrations measured at each of the three experimental trials were averaged (Table 1 ).

\subsection{Satiety Labeled Intensity Magnitude scale}

Mean SLIM ratings increased during each meal, peaking (point of greatest fullness reached) at 15 min during FM and MM, and at $30 \mathrm{~min}$ during SM. Ratings declined thereafter at similar rates independent of

Table 1

Volunteer characteristics. ${ }^{\mathrm{a}}$

\begin{tabular}{|c|c|}
\hline Age $(\text { year })^{\mathrm{b}}$ & $30 \pm 12$ \\
\hline Weight $(\mathrm{kg})^{\mathrm{b}}$ & $82.4 \pm 21.1$ \\
\hline Height $(\mathrm{cm})$ & $173 \pm 8$ \\
\hline BMI $\left(\mathrm{kg} / \mathrm{m}^{2}\right)^{\mathrm{b}}$ & $27.3 \pm 6.7$ \\
\hline Body fat $(\%)^{b}$ & $28.8 \pm 7.8$ \\
\hline $\operatorname{REE}(\mathrm{kJ} / \text { day })^{\mathrm{b}}$ & $6774 \pm 1138$ \\
\hline Normal eating rate $(\mathrm{g} / \mathrm{min})^{\mathrm{b}}$ & $59 \pm 35$ \\
\hline \multicolumn{2}{|l|}{ Fasting values ${ }^{\mathrm{c}}$} \\
\hline Glucose $(\mathrm{mg} / \mathrm{dL})^{\mathrm{b}}$ & $89.1 \pm 6.8$ \\
\hline Insulin $(\mathrm{pg} / \mathrm{mL})^{\mathrm{b}}$ & $419.1 \pm 370.7$ \\
\hline $\mathrm{PP}(\mathrm{pg} / \mathrm{mL})^{\mathrm{b}}$ & $79.2 \pm 62.4$ \\
\hline GLP-1 $(\mathrm{pg} / \mathrm{mL})^{\mathrm{d}}$ & $35.0 \pm 14.7$ \\
\hline Peptide-YY $(\mathrm{pg} / \mathrm{mL})^{\mathrm{e}}$ & $96.7 \pm 44.4$ \\
\hline Cholecystokinin $(\mathrm{pmol} / \mathrm{L})^{\mathrm{e}}$ & $0.83 \pm 0.10$ \\
\hline Leptin $(\mathrm{ng} / \mathrm{mL})^{\mathrm{e}}$ & $8.0 \pm 6.9$ \\
\hline Neuropeptide Y $(\mathrm{pmol} / \mathrm{L})^{\mathrm{e}}$ & $73.2 \pm 21.9$ \\
\hline
\end{tabular}

REE, resting energy expenditure; PP, pancreatic polypeptide; GLP-1, glucagon-like peptide-1.

a Mean $\pm S D$.

b $n=25$.

c Average of three separate trials.

d $n=8$.

e $n=23$. 
meal duration (main effect of time, $P \leq 0.05$; Fig. 2A). Eating slowly delayed TP fullness compared to MM and FM $(P \leq 0.05)$; however, no effects of eating rate on peak fullness or AUC were observed (Table 2). At $15 \mathrm{~min}$, mean fullness was rated lower during SM compared to MM and FM (meal-by-time interaction, $P \leq 0.05$ ). During SM, the mean SLIM rating at $15 \mathrm{~min}$ was equivalent to half of the mean difference between the baseline and peak ratings, concordant with the percentage of the total meal consumed (Fig. 2A).

\subsection{Glucose}

The postprandial glucose response was not affected by eating rate. Mean glucose concentrations increased 15\% above fasting levels by 30 min. Concentrations then fell to a nadir approximately 60 min after peak, gradually increasing thereafter (main effect of time, $P \leq 0.05$; Fig. 2B). No effects of eating rate on peak, TP or AUC were observed (Table 2).

\subsection{Insulin}

The postprandial insulin response was not affected by eating rate. Mean insulin concentrations increased 369\% above fasting levels by
$30 \mathrm{~min}$, then declined to fasting levels by $180 \mathrm{~min}$ (main effect of time, $P \leq 0.05$; Fig. $2 \mathrm{C}$ ). No effects of eating rate on peak, TP or AUC were observed (Table 2 ).

\subsection{Pancreatic polypeptide}

Eating rate altered the postprandial PP response (meal-by-time interaction, $P \leq 0.05$ ). During all meals, mean PP concentrations increased during meal consumption and remained elevated throughout the postprandial period (main effect of time, $P \leq 0.05$; Fig. 2D). Eating quickly attenuated peak PP concentrations $(P \leq 0.05)$, and eating slowly delayed PP time to peak compared to MM $(P \leq 0.05)$; however, PP AUC was not different between meals (Table 2 ).

\subsection{Glucagon like peptide-1}

GLP-1 measurements were only available for eight obese volunteers. The postprandial GLP-1 response was modest (main effect of time, $P=0.09$; Fig. 2E). No effects of eating rate on peak, TP or AUC were observed (Table 2).
A

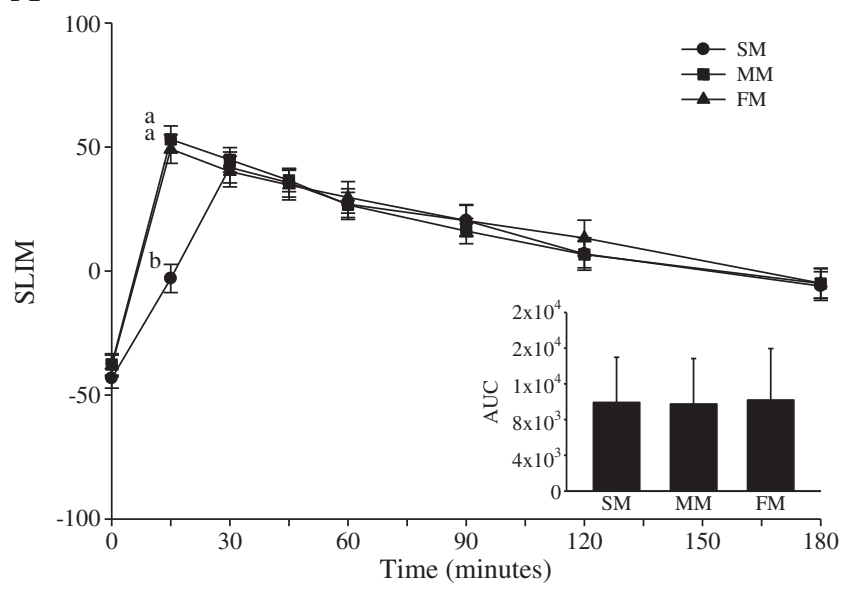

C

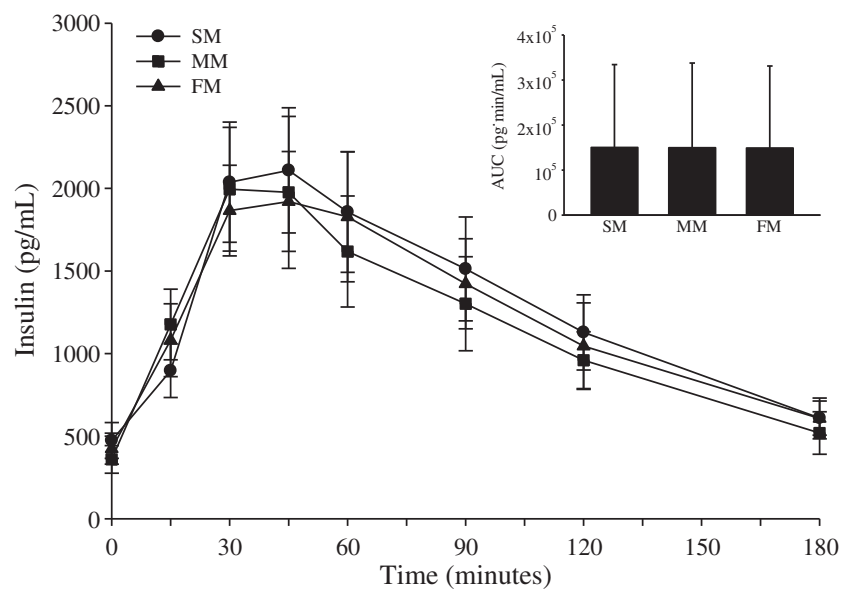

B

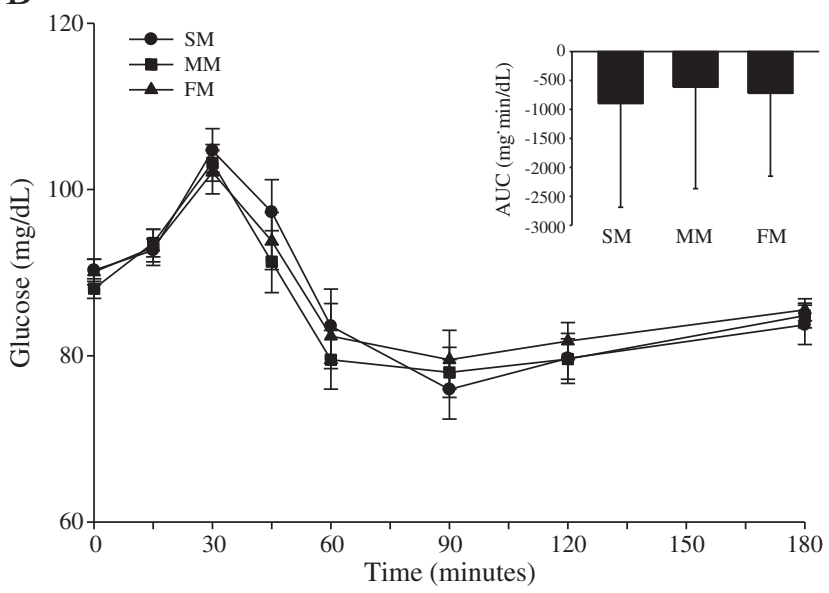

D

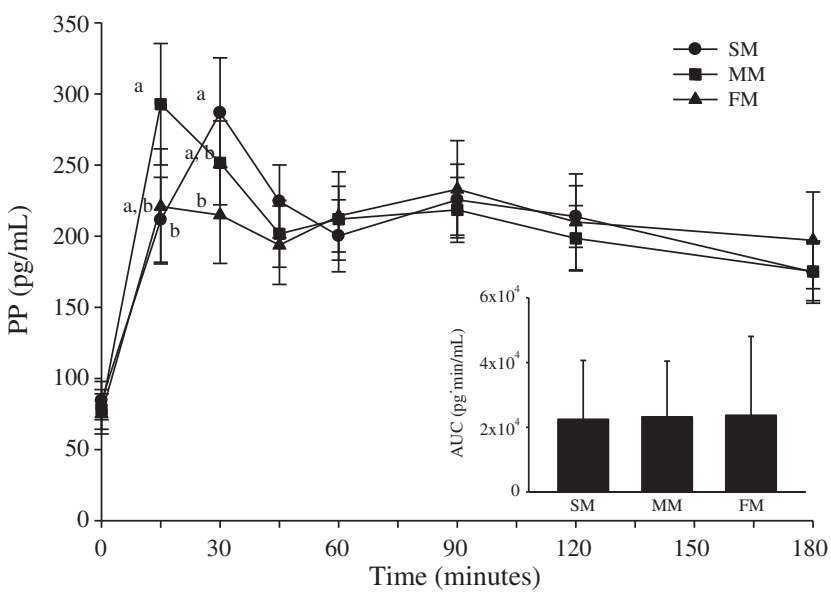

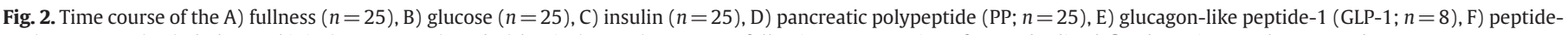

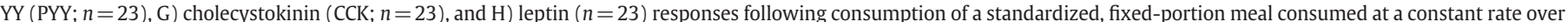

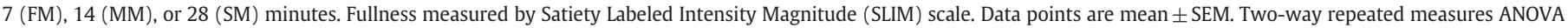

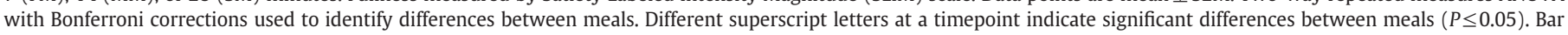
graphs depict area under the curve (AUC; mean $\pm S D$ ) of the postprandial response with respect to increase. 
$\mathrm{E}$

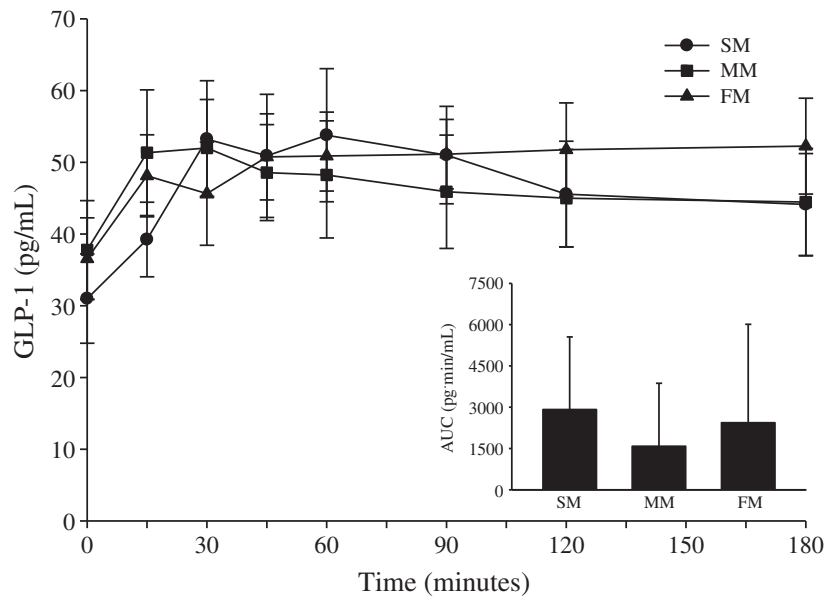

$\mathrm{G}$

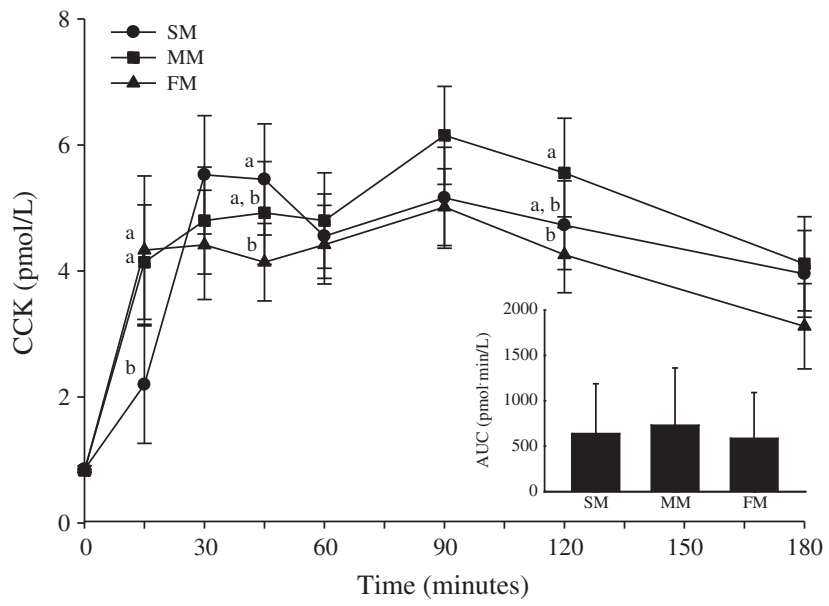

F

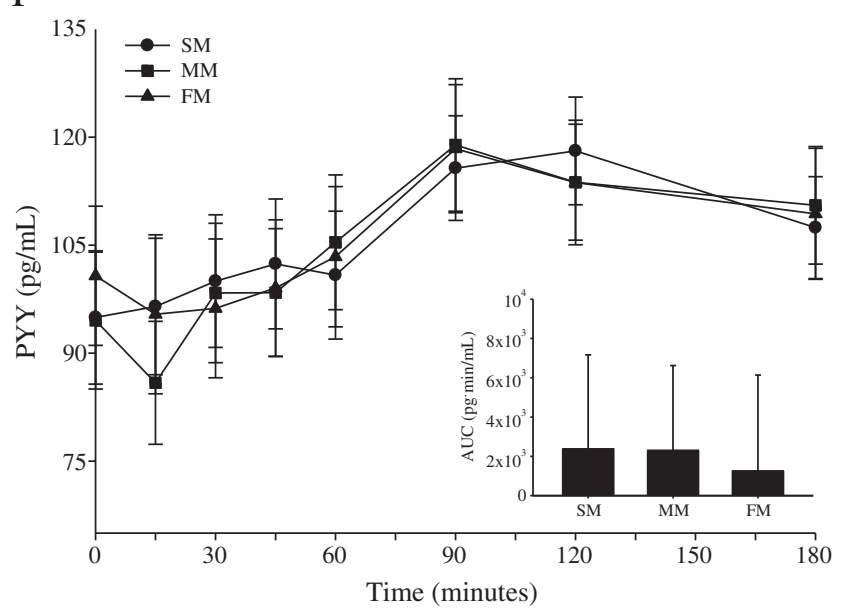

$\mathrm{H}$

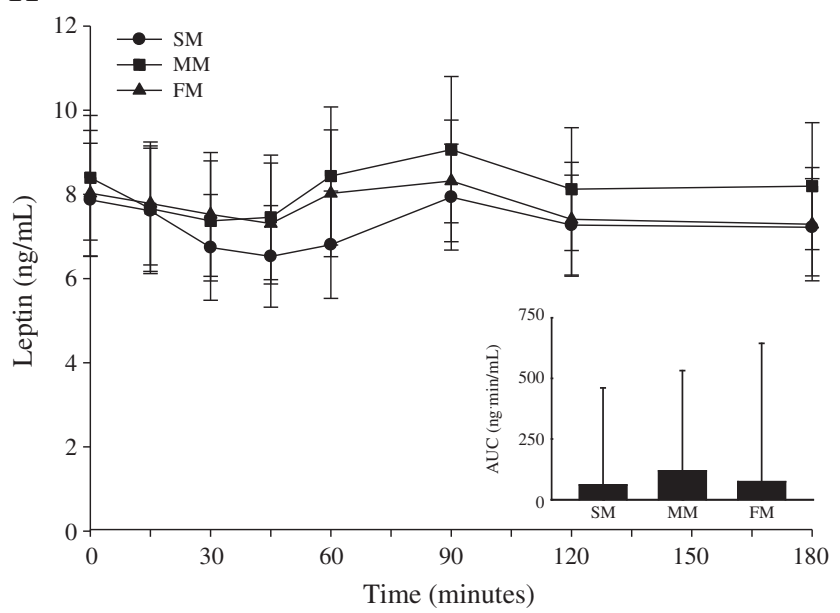

Fig. 2 (continued).

\subsection{Peptide tyrosine-tyrosine}

The postprandial PYY response was not affected by eating rate. Mean concentrations remained stable during the initial 60 min testing period then rose $216 \%$ above fasting levels by $90 \mathrm{~min}$ (main effect of time, $P \leq 0.05$; Fig. $2 F$ ). No effects of eating rate on peak, TP or AUC were observed (Table 2 ).

\subsection{Cholecystokinin}

Mean CCK concentrations rose during each meal and remained elevated throughout the postprandial period (main effect of time, $P \leq 0.05$ ). Eating rate altered the postprandial CCK response (meal-bytime interaction, $P \leq 0.05$; Fig. $2 G$ ). Mean CCK concentrations were lower at 15 min during SM compared to FM and MM, higher at 45 min during MM compared to FM, and higher at 120 min during MM compared to FM $(P \leq 0.05$; Fig. $2 G)$. However, no effects of eating rate on peak, TP or AUC were observed (Table 2).

\subsection{Leptin}

The postprandial leptin response was not affected by eating rate. Mean leptin concentrations appeared to decrease slightly during the postprandial period; however, the main effect of time was not statistically significant $(P=0.10$; Fig. $2 \mathrm{H})$. No effects of eating rate on leptin AUC were observed.

\subsection{Neuropeptide- $Y$}

Mean NPY concentrations were stable during all meals and throughout the postprandial period $(P=0.42)$. No effects of eating rate on NPY AUC were observed (data not shown).

\subsection{Ad libitum energy intake}

Rate of consumption of the fixed-portion meal had no effect on ad libitum energy intake at the following meal. During the ad libitum meal, volunteers consumed $3440 \pm 1609 \mathrm{~kJ}(823 \pm 385 \mathrm{kcal}, 49 \pm 19 \%$ of REE), $3691 \pm 1676 \mathrm{~kJ}(883 \pm 401 \mathrm{kcal}, 52 \pm 19 \%$ of REE), and $3741 \pm$ $1802 \mathrm{~kJ}(895 \pm 431 \mathrm{kcal}, 53 \pm 20 \%$ of REE) following SM, MM, and FM, respectively $(P=0.37)$. To further explore differences in energy intake, ad libitum intake during SM was compared directly to FM. No difference in intake was observed ( $-302 \mathrm{~kJ}$; 95\% CI $-740 \mathrm{~kJ}-135 \mathrm{~kJ}$ ). Fullness following lunch was not different between meals (data not shown). Meal acceptability was not different between meals and was not affected by treatment order in either cohort (data not shown).

\section{Discussion}

This study was designed to explore appetite-signaling mechanisms and satiety. Based on studies indicating that eating slowly may affect energy intake and appetite during an ad libitum meal [13,14], and postprandial endocrine secretion following a fixed-portion meal [18], 
Table 2

Postprandial peak and time to peak of fullness and endocrine mediators of appetite following consumption of a standardized, fixed-portion meal at three different eating rates. $^{\text {a }}$

\begin{tabular}{|c|c|c|c|}
\hline & FM & MM & SM \\
\hline Energy intake $(\mathrm{kJ} / \mathrm{min})^{\mathrm{b}, \mathrm{c}}$ & $388 \pm 65$ & $194 \pm 33$ & $97 \pm 16$ \\
\hline \multicolumn{4}{|l|}{ Fullness (SLIM rating) ${ }^{\mathrm{c}}$} \\
\hline Peak & $52 \pm 29$ & $56 \pm 26$ & $46 \pm 27$ \\
\hline Time to peak (min) & $15(15-90)$ & $15(15-60)$ & $30(30-120)^{x, \dagger}$ \\
\hline \multicolumn{4}{|l|}{ Glucose $^{\mathrm{c}}$} \\
\hline Peak (mg/dL) & $103.5 \pm 13.5$ & $105.3 \pm 10.6$ & $107.8 \pm 15.2$ \\
\hline Time to peak (min) & $30(15-60)$ & $30(15-60)$ & $30(15-60)$ \\
\hline \multicolumn{4}{|l|}{ Insulin ${ }^{c}$} \\
\hline Peak $(\mathrm{pg} / \mathrm{mL})$ & $2307 \pm 1919$ & $2358 \pm 2253$ & $2432 \pm 1986$ \\
\hline Time to peak (min) & $45(15-120)$ & $45(15-120)$ & $45(30-90)$ \\
\hline \multicolumn{4}{|l|}{ Pancreatic polypeptide ${ }^{c}$} \\
\hline Peak $(\mathrm{pg} / \mathrm{mL})$ & $252.1 \pm 204$ & $311.9 \pm 211.2^{\dagger}$ & $298.0 \pm 194.7^{\dagger}$ \\
\hline Time to peak (min) & $30(15-120)$ & $15(15-45)$ & $30(15-60)^{x}$ \\
\hline \multicolumn{4}{|l|}{ Glucagon like peptide- $1^{\mathrm{d}}$} \\
\hline Peak $(\mathrm{pg} / \mathrm{mL})$ & $59.1 \pm 10.3$ & $60.8 \pm 22.9$ & $57.8 \pm 28.9$ \\
\hline Time to peak (min) & $45(15-60)$ & $38(15-90)$ & $60(15-90)$ \\
\hline \multicolumn{4}{|l|}{ Peptide-YY } \\
\hline Peak $(\mathrm{pg} / \mathrm{mL})$ & $126.5 \pm 40.8$ & $131.9 \pm 41.0$ & $131.1 \pm 38.1$ \\
\hline Time to peak (min) & $90(15-180)$ & $90(15-180)$ & $90(15-180)$ \\
\hline \multicolumn{4}{|l|}{ Cholecystokinin $^{\mathrm{e}}$} \\
\hline Peak (pmol/L) & $7.0 \pm 5.3$ & $7.1 \pm 4.0$ & $6.9 \pm 4.8$ \\
\hline Time to peak (min) & $45(15-180)$ & $90(15-120)$ & $45(15-120)$ \\
\hline
\end{tabular}

a Mean \pm SD or median (range). Standardized meal consumed in 7 (FM), 14 (MM) or 28 (SM) minutes. Fullness measured using the Satiety Labeled Intensity Magnitude (SLIM) scale. Repeated measures ANOVA or Friedman's ANOVA used to identify differences between meals.

b Rate of energy intake during fixed-portion meals.

c $n=25$.

d Obese only, $n=8$.

$n=23$.

$x$ Difference from MM, $P \leq 0.05$.

$\dagger$ Difference from FM, $P \leq 0.05$.

we manipulated eating rate during a fixed-portion meal to examine how eating behavior and associated postprandial appetite, and periprandial and postprandial responses of putative endocrine mediators of appetite would affect energy intake at the following meal. A fixed-portion meal, as opposed to a meal consumed ad libitum, was consumed during each of three experimental trials to prevent confounding of postprandial appetite ratings and endocrine responses by differences in self-selected energy intake. The selection of a mixed-macronutrient content meal was intended to elicit responses from each measured hormone. To determine if any observed effects of eating rate and associated postprandial appetite ratings and enteroendocrine hormone responses would translate in measurable behavioral changes, ad libitum energy intake at the next meal was measured. Varying the rate at which the fixed-portion meal was consumed did not alter the magnitude of postprandial changes in fullness or ad libitum intake at the next meal. CCK and PP responses were altered by eating rate during meal consumption and the immediate postprandial period, but not thereafter, and effects of eating rate on additional endocrine mediators of appetite were not observed. Thus, the findings of this study suggest that eating rate does not influence satiety when a fixed-portion is consumed despite a weak effect on the periprandial endocrine response.

Eating rate did not appear to mediate fullness or affect satiety. SLIM ratings at 15 min were lower during SM compared to MM and FM, equivalent to approximately half of the mean difference between baseline and peak SLIM values recorded during SM; however, this difference can be attributed to the fact that at $15 \mathrm{~min}$, only half of the fixed-portion meal had been consumed during SM compared to the entire meal during MM and FM. Concordantly, fullness during SM peaked at $30 \mathrm{~min}$, once the entire meal had been consumed. Though fullness peaked at 15 min during both MM and FM, fullness AUC and peak fullness was not different between the three meals. This observation is interesting as a portion of the meal may have passed through the stomach by 30 min during SM. Due to effects of gastric distention on satiation, it would then be expected that peak SLIM responses would be blunted during SM compared to MM and FM. As this was not observed, these observations suggest factors other than stomach volume contributed to fullness during the fixed-portion meals. However, the influence of these factors did not appear to persist throughout the postprandial period as no differences in the AUC of the SLIM ratings were observed between meals in either cohort, nor was an effect of eating rate on ad libitum energy intake at the following meal documented. Taken together, these observations suggest that manipulating the rate at which a fixed-portion meal is consumed does not influence satiety as measured by energy intake at the subsequent meal.

In lieu of this result, it is important to note differences between this study and recent studies documenting reduced energy intakes during meals eaten slowly compared to quickly [13-15]. The latter studies examined the effects of eating rate on satiation; ad libitum intake was measured during manipulated eating rate meals by allowing volunteers to terminate test meals at their discretion. In contrast, by controlling total energy and volume consumed and then measuring intake at the subsequent meal, this study assessed the effects of eating rate on satiety. Future research examining the endocrine response during meals consumed at different rates but in which total energy intake is not controlled could be a useful approach to investigate potential endocrine mechanisms underlying the effects of eating rate on the development of satiation and ad libitum energy intake during meals.

Studies have documented reduced energy intakes following peripheral administration of CCK [23], PYY [24], and PP [25]. Gut peptides influence energy intake through effects on digestive processes, and through neural and endocrine actions $[2,26]$. For example, CCK is a peptide released primarily from the proximal small intestine and promotes digestion of fats and proteins. Suggested mechanisms accounting for the appetite-suppressing effects of CCK include delayed gastric emptying, stimulation of vagal afferent fibers, and direct activation of appetite centers in the hindbrain and hypothalamus [2-4,26]. Similarly, the PP-fold family of peptides, which includes the peptides PP and PYY and the orexigenic neuropeptide NPY, has direct neural effects on central appetite centers as evidenced by high affinity binding of each peptide to the Y family of receptors within the hypothalamus [2]. Both PP and PYY may also affect appetite through stimulation of vagal afferent fibers and decreased gastrointestinal motility [4]. Thus, investigating factors that may mediate the release of these peptides could provide insight into relationships between behavior, physiology and appetite.

In this study, eating quickly appeared to attenuate the postprandial PP peak compared to eating at moderate and slow rates. Further, eating slowly delayed PP time to peak compared to eating at a moderate rate. However, despite the periprandial effects of eating rate on PP concentrations, mean concentrations were stable and not different between meals from 45 to 180 min indicating that eating rate had no persisting effect on the PP response. Eating rate also altered the periprandial CCK response; however, no between meal differences in CCK AUC, peak or TP were observed. Thus, the effects of eating rate on the PP and CCK responses were limited to the periprandial period and did not influence postprandial fullness or energy intake at the subsequent meal. The observed periprandial effects; however, may be consistent with the putative role of CCK and $\mathrm{PP}$ as satiation hormones.

In contrast to our findings, the results of one recent study suggested that fast eating rates influence postprandial PYY and GLP-1 responses to a mixed meal. Kokkinos et al. [18] measured hunger, fullness, and concentrations of PYY, GLP-1 and ghrelin, an orexigenic gut hormone, in volunteers consuming a fixed-portion $675 \mathrm{kcal}$ meal over 5 or $30 \mathrm{~min}$. The authors reported that eating quickly had no effect on subjective appetite ratings or the postprandial ghrelin response, but attenuated the postprandial PYY and GLP-1 responses. The influence of the depressed 
PYY and GLP-1 responses on prospective energy intake however was not measured. Differences in the methods used to control eating rate might explain the incongruous results between that study and ours. In contrast to the consistent eating rate maintained throughout each meal in our study, Kokkinos et al. controlled eating rate by providing equal portions of a test meal every $5 \mathrm{~min}$ (i.e., 2 portions of $337.5 \mathrm{kcal}$ or 7 portions of $\sim 96.5 \mathrm{kcal}$ ) and requiring volunteers to consume each portion in less than $1 \mathrm{~min}$. As cephalic stimuli stimulate gastrointestinal responses that initiate digestive processes, repeated periods of ingestion followed by restriction from eating may create a physiological response more similar to that associated with multiple eating occasions as opposed to the response associated with a single eating event by repeatedly stimulating cephalic phase digestive responses. Peptide-YY and GLP-1 are putative inhibitors of the cephalic phase digestive response [27]; thus, repeated cephalic stimulation may perturb the normal patterns of hormone secretion observed during a single eating event, augmenting postprandial PYY and GLP-1 responses. Alterations in gastrointestinal transit time due to differences in viscosity between the meals used in these two studies may further explain the discrepant findings [6]. Importantly, Kokkinos et al. observed no effect of eating quickly on postprandial appetite ratings, despite attenuated PYY and GLP-1 responses. Thus, while eating rate altered the postprandial endocrine response in that trial, this effect had no appreciable impact on appetite and presumably would not have had altered prospective energy intake.

The absence of an effect of eating rate on leptin and NPY in the current trial was not unexpected. Leptin mediates energy homeostasis through direct effects on neural groups throughout the CNS [28]. Like insulin, leptin is secreted in proportion to body fat stores [29], acting as a long-term regulator of energy intake [2]. In weight-stable individuals, the periprandial and acute postprandial $(0-3 \mathrm{~h})$ leptin response appears minimal [3,30,31], and demonstrates little association with hunger and satiety $[3,32,33]$. Likewise, NPY regulates longterm energy balance, as expression of the neuropeptide is modulated by alterations in leptin and insulin concentrations associated with energy balance perturbations [34]. Further, NPY secretion is episodic and, though some evidence exists for an acute glucose-mediated stimulation of hypothalamic NPY expression [35,36], peripheral NPY concentrations may not be modulated by acute feeding.

Limitations to the current study include the meal and feeding protocol used. The amount of food provided at the fixed-portion meal may have been too much or the intermeal interval too short to mimic a normal eating pattern. For example, SLIM ratings immediately prior to the ad libitum meal were above those at baseline suggesting that under free-living conditions, these volunteers may have delayed initiating the next meal. However, with the exception of two volunteers, all volunteers consumed more than $250 \mathrm{kcal}$ ad libitum indicating that they were experiencing at least a slight amount of hunger by $180 \mathrm{~min}$. Offering only a single food item at the ad libitum meal may be another limitation. We chose a single food to avoid confounding effects that might be introduced by food items of differing composition and the multiple ways these foods could be combined. However, relying on only a single food may have masked effects of eating rate on ad libitum intake due to influences on sensoryspecific satiety [37]. Our results might also be limited to mixedcomposition meals as several putative enteroendocrine hormones are sensitive to the type of carbohydrate in the meal as well as the macronutrient composition of the meal [5]. Inclusion of smokers in the trial may also affect outcomes. Volunteers were required to abstain from smoking for at least $12 \mathrm{~h}$ prior to and throughout experimental visits, and volunteers served as their own controls; however, the possible effects of abstaining from smoking on appetite cannot be addressed. Finally, menstrual cycle phase was not controlled for in this trial. No meal-by-sex interactions were observed for baseline SLIM ratings or baseline hormone concentrations however, indicating that women did not demonstrate larger between meal differences in baseline measures compared to men. Nonetheless, menstrual cycle phase has been shown to affect appetite [38] and therefore may have influenced energy intake during the ad libitum meal. Recent findings also suggest that menstrual cycle phase may alter postprandial hormone responses [39]. Future studies examining energy intake and metabolism in women should control for effects of menstrual cycle phase.

A combination of hedonic, environmental and physiologic factors influence how much one eats. Identifying factors that modulate appetite-signaling mechanisms could support development of effective, physiologically based weight management strategies. The results of this study suggest that the rate at which a fixed-portion is consumed has little effect on the postprandial enteroendocrine response and is unlikely to alter energy intake during the subsequent meal. Thus, eating rate appears only to influence appetite and energy intake within an ad libitum meal [13].

\section{Acknowledgements}

The authors wish to acknowledge the volunteers who participated in this research. Michael Stanger, SSG Jay O'Hara, SGT Ryan Regalia and SSG Bryan Wiley all made significant technical contributions to the experiments detailed in this manuscript. Finally, the authors wish to acknowledge Dr. Jennifer Rood and her team at the Pennington Biomedical Research Center for performance of the assays. Research funded by US Army Medical Research and Materiel Command.

\section{References}

[1] World Health Organization. Obesity: preventing and managing the global epidemic. Report of a WHO consulation, 894. WHO Technical Report Series; 2000

[2] Wren AM, Bloom SR. Gut hormones and appetite control. Gastroenterology 2007; 132:2116-30.

[3] de Graaf C, Blom WA, Smeets PA, Stafleu A, Hendriks HF. Biomarkers of satiation and satiety. Am J Clin Nutr 2004;79:946-61.

[4] Chaudhri O, Small C, Bloom S. Gastrointestinal hormones regulating appetite. Philos Trans R Soc Lond B Biol Sci 2005;361:1187-209.

[5] Karhunen LJ, Juvonen KR, Huotari A, Purhonen AK, Herzig KH. Effect of protein, fat, carbohydrate and fibre on gastrointestinal peptide release in humans. Regul Pept 2008;149:70-8.

[6] Juvonen KR, Purhonen AK, Salmenkallio-Marttila M, Lahteenmaki L, Laaksonen DE, Herzig KH, et al. Viscosity of oat bran-enriched beverages influences gastrointestinal hormonal responses in healthy humans. J Nutr 2009;139:461-6.

[7] Barkeling B, Rossner S, Sjoberg A. Methodological studies on single meal food intake characteristics in normal weight and obese men and women. Int J Obes Relat Metab Disord 1995;19:284-90.

[8] Hill SW, McCutcheon NB. Contributions of obesity, gender, hunger, food preference, and body size to bite size, bite speed, and rate of eating. Appetite 1984;5:73-83.

[9] Laessle RG, Lehrke S, Duckers S. Laboratory eating behavior in obesity. Appetite 2007;49:399-404.

[10] Llewellyn CH, van Jaarsveld $\mathrm{CH}$, Boniface D, Carnell S, Wardle J. Eating rate is a heritable phenotype related to weight in children. Am J Clin Nutr 2008;88:1560-6.

[11] Otsuka R, Tamakoshi K, Yatsuya H, Murata C, Sekiya A, Wada K, et al. Eating fast leads to obesity: findings based on self-administered questionnaires among middle-aged Japanese men and women. J Epidemiol 2006;16:117-24.

[12] Sasaki S, Katagiri A, Tsuji T, Shimoda T, Amano K. Self-reported rate of eating correlates with body mass index in 18-y-old Japanese women. Int J Obes Relat Metab Disord 2003;27:1405-10.

[13] Andrade AM, Greene GW, Melanson KJ. Eating slowly led to decreases in energy intake within meals in healthy women. J Am Diet Assoc 2008;108:1186-91.

[14] Martin CK, Anton SD, Walden H, Arnett C, Greenway FL, Williamson DA. Slower eating rate reduces the food intake of men, but not women: implications for behavioral weight control. Behav Res Ther 2007;45:2349-59.

[15] Zijlstra N, de Wijk RA, Mars M, Stafleu A, de Graaf C. Effect of bite size and ora processing time of a semisolid food on satiation. Am J Clin Nutr 2009;90:269-75

[16] Benelam B. Satiation, satiety and their effects on eating behaviour. Nutr Bull 2009;34:126-73.

[17] Kral TVE, Rolls BJ. Energy density and portion size: their independent and combined effects on energy intake. Physiol Behav 2004;82:131-8.

[18] Kokkinos A, Le Roux CW, Alexiadou K, Tentolouris N, Vincent RP, Kyriaki D, et al. Eating slowly increases the postprandial response of the anorexigenic gut hormones, peptide YY and glucagon-like eptide-1. J Clin Endocrinol Metab 2009;95:333-7.

[19] Garner DM, Olmsted MP, Bohr Y, Garfinkel PE. The eating attitudes test: psychometric features and clinical correlates. Psychol Med 1982;12:871-8. 
[20] Cunningham JJ. Body composition as a determinant of energy expenditure: a synthetic review and a proposed general prediction equation. Am J Clin Nutr 1991;54:963-9.

[21] Cardello AV, Schutz HG, Lesher LL, Merrill E. Development and testing of a labeled magnitude scale of perceived satiety. Appetite 2005;44:1-13.

[22] Pruessner JC, Kirschbaum C, Meinlschmid G, Hellhammer DH. Two formulas for computation of the area under the curve represent measures of total hormone concentration versus time-dependent change. Psychoneuroendocrinology 2003;28:916-31.

[23] Kissileff HR, Pi-Sunyer FX, Thornton J, Smith GP. C-terminal octapeptide of cholecystokinin decreases food intake in man. Am J Clin Nutr 1981:34:154-60.

[24] Batterham RL, Bloom SR. The gut hormone peptide YY regulates appetite. Ann NY Acad Sci 2003;994:162-8.

[25] Batterham RL, Le Roux CW, Cohen MA, Park AJ, Ellis SM, Patterson M, et al. Pancreatic polypeptide reduces appetite and food intake in humans. J Clin Endocrinol Metab 2003;88:3989-92.

[26] Cummings DE, Overduin J. Gastrointestinal regulation of food intake. J Clin Invest 2007:117:13-23

[27] Katschinski M. Nutritional implications of cephalic phase gastrointestinal responses. Appetite 2000;34:189-96.

28] Ahima RS. Adipose tissue as an endocrine organ. Obesity 2006;14:242S-9S.

29] Considine RV, Sinha MK, Heiman ML, Kriauciunas A, Stephens TW, Nyce MR, et al. Serum immunoreactive-leptin concentrations in normal-weight and obese humans. N Engl J Med 1996;334:292-5.

[30] Raben A, Gerholm-Larsen L, Flint A, Holst JJ, Astrup A. Meals with similar energy densities but rich in protein, fat, carbohydrate, or alcohol have different effects on energy expenditure and substrate metabolism but not on appetite and energy intake. Am J Clin Nutr 2003;77:91-100.

[31] Korbonits M, Trainer PJ, Little JA, Edwards R, Kopelman PG, Besser GM, et al. Leptin levels do not change acutely with food administration in normal or obese subjects, but are negatively correlated with pituitary-adrenal activity. Clin Endocrinol (Oxf) 1997;46:751-7.

[32] Joannic JL, Oppert JM, Lahlou N, Basdevant A, Auboiron S, Raison J, et al. Plasma leptin and hunger ratings in healthy humans. Appetite 1998;30:129-38.

[33] Romon M, Lebel P, Velly C, Marecaux N, Fruchart JC, Dallongeville J. Leptin response to carbohydrate or fat meal and association with subsequent satiety and energy intake. Am J Physiol 1999;277:E855-61.

[34] Hillebrand JJ, de WD, Adan RA. Neuropeptides, food intake and body weight regulation: a hypothalamic focus. Peptides 2002;23:2283-306.

[35] Leibowitz SF, Wortley KE. Hypothalamic control of energy balance: different peptides, different functions. Peptides 2004;25:473-504

[36] Wang J, Dourmashkin JT, Yun R, Leibowitz SF. Rapid changes in hypothalamic neuropeptide $Y$ produced by carbohydrate-rich meals that enhance corticosterone and glucose levels. Brain Res 1999;848:124-36.

[37] Rolls BJ. Sensory-specific satiety. Nutr Rev 1986;44:93-101.

[38] Buffenstein R, Poppitt SD, McDevitt RM, Prentice AM. Food intake and the menstrual cycle: a retrospective analysis with implications for appetite research. Physiol Behav 1995:58:1067-77.

[39] Brennan IM, Feltrin KL, Nair NS, Hausken T, Little T], Gentilcore DG, et al. Effects of the phases of the menstrual cycle on gastric emptying, glycemia, plasma GLP-1, and insulin, and energy intake in healthy lean women. Am J Physiol Gastrointest Liver Physiol 2009;297:602-10. 